\title{
Apropriação do relevo e paisagens tecnogênicas: discussões acerca do ensino da geomorfologia com base em exemplos cariocas e fluminenses
}

\author{
Cleber Marques de Castro \\ Depto. de Turismo, UERJ, Teresópolis, RJ \\ cleber.castro@uerj.br \\ Telma Mendes da Silva \\ Depto. de Geografia, UFRJ, Rio de Janeiro, RJ \\ telmendes@globo.com
}

\begin{abstract}
Nowadays it is still common to find teaching approaches centered on the description of forms and phenomena rather than on processes analysis. This article proposes that the teaching geomorphology should focus on the processes of appropriation and transformation of landscapes without distance itselffrom social demands and land management solutions. The landforms of Rio de Janeiro are used as the objects of the proposed critical and inclusive teaching method, understanding that society acts as a geomorphological agent - an aspect that characterizes Technogene. The geomorphological mapping and an appropriate cartographic representation are fundamental instruments to understanding the dynamics of landscape evolution. Thus, understanding social appropriation of landscape provides elements for an education that demonstrates the environmental risks and conflicts of land use forms. The teaching approaches in Geomorphology can be captivating when we put in evidence its importance in the spatial organization of society.
\end{abstract}

KEYWORDS: Geomorphology, landscape, Technogene, Rio de Janeiro.

RESUMO Atualmente ainda é possível encontrar abordagens didáticas centradas na descrição de formas e fenômenos em detrimento do estudo dos processos. O presente artigo propõe que o ensino de Geomorfologia enfoque os processos de apropriação e transformação de paisagens sem distanciar-se das demandas sociais e da busca por soluções de problemas relacionados à gestão do território. O relevo do Rio de Janeiro é usado como objeto da proposta de ensino crítico e inclusivo, entendendo que a sociedade atua como agente geomorfológico - aspecto que caracteriza o Tecnógeno. Os mapeamentos geomorfológicos e a sua representação cartográfica adequada são instrumentos fundamentais para a compreensão da dinâmica de evolução da paisagem. Por fim, compreender as formas de apropriação da paisagem pelos diferentes grupos sociais fornece elementos para uma educação que evidencie os riscos e conflitos ambientais das diversas formas de uso do solo. O ensino de Geomorfologia pode ser cativante na medida em que colocamos em evidência a sua importância no processo de organização espacial da sociedade.

PALAVRAS CHAVE: Geomorfologia, paisagem, Tecnógeno, Rio de Janeiro. 


\section{Introdução}

O relevo do planeta e suas especificidades condicionam a ocupação das sociedades, assim como os tipos e a distribuição dos solos, a vegetação, algumas características climáticas locais, dentre outros aspectos. Os estudos geomorfológicos podem enfocar a gênese e o desenvolvimento das formas de relevo, em escala geológica, engendradas pelo movimento dialético permanente entre forças internas (endógenas) e forças externas (exógenas) da Terra e, em escala histórica, procurando identificar o papel da transformação das formas de relevo a partir de diferentes escalas de apropriação.

Neste sentido a Ciência Geomorfológica é fundamental para a compreensão da gênese do relevo stricto sensu, e para a reprodução da sociedade e de suas atividades (exploração de recursos naturais, assentamentos e ocupação urbana, processos erosivos, enchentes e inundações, seu significado geopolítico, dentre outros).

Posto a importância desta Ciência em seus variados aspectos, as perguntas que norteiam este artigo são: como abordar conteúdos e conhecimentos de uma Geografia que se renova constantemente? $\mathrm{O}$ ensino de Geomorfologia deve estar embasado apenas nas descrições e reconhecimento das formas de relevo? Existem abordagens que contribuam para uma leitura e ensino críticos da Geomorfologia?

Começamos a pensar nas respostas destas perguntas a partir da discussão trazida por Oliva (1999). O referido autor afirma que, a despeito do processo de renovação na Geografia, ainda encontra-se muitos livros didáticos que mantem um "formato jornalístico", isto é, que possuem uma linguagem simplificada e que prezam por uma transmissão/comunicação dos fatos, sem criar margem para reflexões e debates críticos.

Desta forma, o presente artigo visa contribuir para o debate acerca do ensino do relevo, apontando para o desenvolvimento de abordagens de trabalho que privilegiem um conteúdo crítico, articulado com as questões socioambientais e políticas, superando as noções (que ainda encontram ressonância) de relevo como fornecedor de recursos naturais ou como palco inerte da história.

\section{Por uma pedagogia da Geomorfologia}

Sem a pretensão de esgotar o debate acerca da transposição de conteúdos universitários para o ensino escolar, mas de contribuir para este debate, buscamos avançar respondendo a indagação-título deste item, no intuito de discutir os desvios existentes no percurso academia-professores-alunos e a forma com que os conteúdos são apresentados.

Conforme a proposta de Simielli (1999), a transposição didática se caracteriza como uma verdadeira (re)construção do conhecimento geográfico, já que as finalidades e práticas geográficas não são as mesmas na universidade e no ensino fundamental e médio escolar. Os desvios, ou seja, as diferenciações de leitura da Geomorfologia em diferentes fases da vida escolar se concretizam na medida em que estas reconstruções são feitas, em diferentes fases do processo de ensino-aprendizagem, a saber: (i) reconstrução no nível dos programas oficiais, em que apenas uma parte da temática acadêmica será utilizada para determinar os conteúdos escolares; (ii) reconstrução no nível do professor em que partindo dos programas oficiais os professores elaboram sua prática de ensino-aprendizagem reconstruindo os conteúdos segundo suas próprias concepções teórico-metodológicas; (iii) reconstrução no nível do processo ensino-aprendizagem em que os exercícios práticos e de fixação de conteúdo são reconstruídos a partir da experiência de sua aplicação em sala de aula, bem como das dificuldades e das respostas (reações) dos alunos; e (iv) reconstrução no nível do aluno, o saber realmente adquirido pelo aluno, também passa por uma reconstrução.

Entretanto, a despeito dos desvios, não devemos buscar a construção de um conhecimento geográfico simplificado, palatável, como se essa simplificação implicasse em transformar o conteúdo escolar em mero resumo do que é produzido nas universidades. Neste sentido, é importante conhecer a dinâmica das partes que se constituem como responsáveis pela construção do conhecimento, isto é, a universidade por um lado e a escola por outro.

Oliva (1999) tece considerações acerca das relações universidade - escola para o ensino de Geografia e sintetiza dois diferentes cenários. Primeiramente, preocupado com a renovação do conhecimento geográfico nas escolas, o autor mostra que a maior parte dos professores do ensino médio e fundamental é formada em instituições privadas de ensino, que ao contrário das universidades públicas, reproduzem em sua grande maioria, uma geografia tradicional, alheia às renovações teóricas e metodológicas. Segundo Oliva (1999): 
(...) apenas alguns estabelecimentos (em geral estatais) dedicam-se a produção de conhecimento novo e estão em contato direto com as formas de renovação da geografia (...). Desse modo, o conjunto imenso de instituições privadas de ensino superior em que predominam cursos de licenciatura em geografia reproduzem, na maioria dos casos, uma geografia tradicional, congelada e mumificada, praticamente alheia à renovação em andamento (p.37).

Outro cenário elaborado por Oliva (op.cit.) para o ensino básico refere-se, por um lado a que as escolas públicas encontram-se sem perspectivas e enfraquecidas, com o quadro docente sem incentivo e valorização para a realização de aperfeiçoamento. Por outro lado as escolas privadas funcionam dentro da lógica de mercado, tornando-se "empreendimentos educacionais". De acordo com Cavalcanti (2004), o movimento de renovação da Geografia, que nos últimos vinte anos abriu espaço para a discussão acerca da reformulação do ensino de Geografia, ainda tem efeitos modestos na prática docente.

Uma crítica importante que pode ser estendida ao ensino de Geomorfologia diz respeito aos livros didáticos, um importante instrumento na utilização para aquisição de conhecimento para os alunos e para o professor. Uma parte dos livros de Geografia ainda não acompanhou as significativas mudanças teóricas dos últimos anos e trazem consigo um pedagogismo exacerbado, que segundo Oliva (1999) caracteriza-se pela ideia falaciosa de que os livros didáticos não podem utilizar-se de uma linguagem conceitual, acadêmica. Faz-se então valer um imperativo pedagógico que detém o monopólio da comunicação e da linguagem, que busca uma simplificação dos conteúdos, bem como um ocultamento de posições divergentes, em nome de um aprendizado mais fácil e concreto. Novamente citando Oliva (1999):

A simplicidade traz algumas consequências inaceitáveis, que enfraquecem o valor educativo da geografia (...). Assim, conceitos viram realidade, dissolvendo-se no interior dela. Por exemplo: quem disse que as atividades econômicas dividem-se naturalmente, em três setores (primário, secundário e terciário)? Esta é uma classificação conceitual, cada vez menos útil e que não traduz a realidade. Outra consequência do formato afirmativo dos livros é o ocultamento das divergências. Com isso retira-se o leitor - no caso o aluno - do fluxo vivo do pensamento, apartando-o da vida real (...). O mais grave é que essa deformação da realidade vem quase sempre mascaradas como necessidade pedagógica, (...) pois de outra maneira os pobres professores do ensino médio e os alunos não entenderiam (p.40).

Esta pedagogia dos livros didáticos, que prima pela simplificação, produz e induz a uma série de equívocos. Ross (1985) já advertia sobre a desatualização dos livros de Geografia para o ensino fundamental e médio, reproduzindo informações da década de 1940 e deixando de lado o avanço da Geomorfologia nas últimas décadas. Um grave problema, segundo esse autor, é a confusão sobre a idade e gênese das estruturas e das formas de relevo. Constantemente lê-se nos livros afirmativas quanto à idade do relevo brasileiro: "muito antigo", "velhos planaltos", entre outros. Todavia, estrutura e forma não são sinônimos e não possuem necessariamente a mesma idade (ROSS 1985). No Brasil, as estruturas que sustentam as formas são, via de regra, antigas, datadas do pré-Cambriano (4,6 bilhões de anos), enquanto que as formas atuais foram moldadas, sobretudo, nos últimos milhares de anos.

Outra crítica que se faz necessária, portanto, diz respeito à redução que é realizada na explicação das formas de relevo. Retiram-se as explicações acerca da gênese e deixa-se de lado a investigação sobre o desenvolvimento atual das formas (isto é, os estudos dos processos geomorfológicos continentais, costeiros e marinhos). $\mathrm{O}$ tratamento do relevo pelos livros didáticos e consequentemente em sala de aula resume-se aos conceitos de planalto, planície, depressão e montanha, como também o reduzem a mera descrição de formas geométricas ou a diferenças de altitude.

Tais definições engessam o conhecimento e não fornecem aos alunos a devida noção do relevo, ou seja, de transformação constante em escala de tempo geológica (jogo dialético entre as forças interna e externa da Terra, mesmo que seja muitas vezes imperceptível para a identificação humana) e em escala de tempo histórica (alterações produzidas pelo homem, direta ou indiretamente), isto é, o Tecnógeno (Ter-Stepanian 1988).

Peloggia (1997) afirma que as ações do homem sobre a natureza, através das atividades produtivas, produzem efeitos geológico-geomorfológicos importantes, a ponto de ser caracterizado um novo período geológico para caracterizar esta ação que seria o Tecnógeno. Este autor se refere a feições 
de relevo ou depósitos gerados direta ou indiretamente pelo trabalho humano que pode se dar em três níveis: alterações fisiográficas da paisagem (retificações de canais de drenagem, terraplanagens, áreas de mineração, etc); alterações da fisiologia das paisagens (criação, indução ou modificação do comportamento dos processos da dinâmica externa da Terra, aumento de erosão e da carga sedimentar, escorregamentos, escoamentos, etc) e criação de depósitos superficiais correlativos (os depósitos tecnogênicos, configurando novos marcos estratigráficos, tais como aterros e depósitos de lixo, por exemplo). Desta forma, é muito importante que a sociedade (ou a ação do homem) seja incluída como um agente modelador do relevo.

De acordo com Ter-Stepanian (1988) o século XX foi caracterizado pelo aumento da interferência humana na "natureza harmônica" estabelecida durante os últimos dois bilhões de anos. $\mathrm{O}$ autor correlaciona uma série de processos endógenos e exógenos de caráter natural e seus correspondentes de caráter tecnogênico. Por exemplo, o processo natural de denudação possui como um processo tecnogênico correlato, os cortes de solo para construção civil. A lenta formação natural do relevo, por um lado, pode ser correlacionada às rápidas transformações tecnógenas oriundas da mineração, da construção de canais artificiais, de aterros, dentre tantos outros. Tais correlações são úteis, inclusive no contexto da sala de aula, para estabelecer a influência humana na paisagem e no próprio relevo.

E, assim, o ensino da Geomorfologia pode estar aliado aos conceitos de paisagem e de lugar, contribuindo para uma percepção geográfica mais estruturada da situação do aluno no bairro, no município, na sua vida cotidiana. O relevo pode ser um elemento fundamental para a vida social das pessoas, influenciando suas práticas sociais. O exercício de relacionar o sítio com a posição da residência do aluno, ou da própria escola, por exemplo, pode ajudá-lo a compreender o porquê da recorrência de enchentes em épocas de chuvas, da ocorrência de escorregamentos, dentre vários outros exemplos de processos geomorfológicos. Desta maneira a Geomorfologia atuaria no intuito de superar representações sociais idealizadas e estereotipadas do conceito de paisagem e de lugar. $\mathrm{Ou}$ seja, desses conceitos, em conjunto com a análise geomorfológica, contribuírem para a constituição da noção de espaço vivido e construído. Assim, a paisagem deixaria de ser definida por muitos alunos e pessoas como "um lugar bonito" e o conceito de lugar, por outro lado, adquiriria mais concretude ${ }^{11}$.

Nesta perspectiva, os materiais didáticos e a própria prática docente devem priorizar o estudo da Geomorfologia a partir de um referencial teórico acadêmico que considere a realidade e o cotidiano dos alunos em questão. A mera apresentação de estatísticas e medidas, a valorização do aspecto "visível" do relevo e a memorização são práticas inadequadas à apreensão da evolução dinâmica e complexa das formas de relevo, engendrada pela dialética entre as forças endógenas e exógenas do planeta em escala de tempo geológica.

A proposta de trabalho deve-se calcar na caracterização deste jogo de forças antagônicas e complementares conjuntamente, em escala histórica, com o desvendar das contradições da sociedade no processo de apropriação do relevo pelos diferentes atores sociais, a partir do desenvolvimento de competências e habilidades nos diferentes níveis de ensino. A Geomorfologia, pois, não pode distanciar-se das demandas sociais e da busca por soluções de problemas relacionados à gestão do território.

\section{Geomorfologia e apropriação do relevo: exemplos cariocas e fluminenses}

Vários são os trabalhos acadêmicos acerca do processo de apropriação do relevo e ocupação do território, assim como sobre a transformação das formas de relevo e os impactos e riscos ambientais decorrentes desta apropriação. O debate sobre a apropriação dos recursos naturais e a ocupação do território no Brasil figura como uma abordagem que permite uma aproximação com a Geomorfologia, sobretudo no que tange ao ensino dos processos geomorfológicos, relacionados à dinâmica fluvial, à dinâmica das encostas e à dinâmica costeira.

Esta abordagem torna-se possível a partir de uma concepção crítica da ocupação territorial, em diferentes escalas de análise, evidenciando as formas de apropriação do território através das necessidades engendradas pelo modo de produção e pelas formas de trabalho empregadas. Analisando tanto em escala nacional, como no que concerne ao atual estado do Rio de Janeiro é importante destacarmos que ao longo do tempo, as formas de trabalho adquiriram diferentes níveis de complexidade. A urbanização e a industrialização brasileira, em seus

1 Os dados e a análise gerada pela pesquisa de Cavalcanti (2004) evidenciam como os conceitos de paisagem e de lugar são ainfa bastante estereotipados, assim como a própria noção de relevo está muito associada à ideia de paisagem. 
aspectos mais amplos, bem como a incorporação de novas tecnologias no processo produtivo, contribuíram para diferentes fases de conhecimento e controle do território nacional, visando a apropriação dos recursos naturais disponíveis.

A apropriação do relevo deve-se, segundo Casseti (1999) a uma mudança de paradigma, gerado pela conjunção das teorias e descobertas de Descartes (séc. XVII) e Newton (séc. XVIII), que retiram da natureza seu viés religioso e sagrado. Surge desta forma uma natureza externa ao homem, mecânica e mensurável, que permite quantificação e controle. Legitima-se, assim, a apropriação do relevo, entendido como meio de produção e fornecedor de recursos naturais.

Conforme afirma Jean Tricart (1956) é o tipo de organização social que comanda a atitude do homem em relação à natureza e a transformação das formas de relevo é fruto dessa organização social (e econômica). As transformações ambientais, portanto, resultam da necessidade da sociedade ocupar determinada área, isto é, porções do relevo (baixadas, planícies, encostas, várzeas) que sofrerão com diferentes formas da apropriação (usos/ finalidades) e ocupação (aterros, cortes do terreno, desmatamentos, canalizações, barragens e desvios de rios, entre outros) que poderão, por sua vez, propiciar riscos ambientais.

A história da cidade do Rio de Janeiro está intrinsecamente relacionada com a geomorfologia local, ou seja, com as possibilidades e restrições que o sítio forneceu às ocupações. Dentre aspectos importantes para a ocupação da região, desde os tempos da fundação da cidade (em $1^{\circ}$ de março de 1565), destacamos: a instalação da população nas baixadas adjacentes à Baía de Guanabara, em boa parte paludosa e que demandou ao longo do processo de ocupação diversas intervenções de engenharia (drenagens, aterros e canalizações de rios); bem como a presença de morros e dos maciços costeiros (Pedra Branca, Tijuca, Gericinó-Mendanha) que caracterizam a rede de drenagem em escala regional, fornecendo água e sedimentos para as baixadas. A complexa dinâmica social e de ocupação/uso do território transformou o binômio maciços/baixadas em um grave problema socioambiental na medida em que a ocupação por sua vez potencializa as enchentes, movimentos gravitacionais de massa e a erosão de encostas.

A análise de dois trabalhos que abordam diferentes situações de ocupação e uso do território no estado do Rio de Janeiro é um bom exemplo para ilustração do que podemos denominar de paisagens tecnogênicas.

O trabalho de Abreu (1992) evidencia a relação da cidade do Rio de Janeiro com o maciço da Tijuca, explorando suas várias funções desde o início do processo de ocupação: fornecedor de madeira, lenha e rochas; ponto estratégico para a proteção da cidade; área agrícola; abrigo de quilombos; área de instalação de fábricas visando o aproveitamento hidráulico e fornecedor de água para o abastecimento da cidade.

Dentre estas funções, duas chamam a atenção. Em primeiro lugar, o sítio, além de fornecer uma posição estratégica de defesa para a cidade que então crescia, serviu conforme apontado por Abreu (1992) para dividir a cidade em pelo menos duas zonas, a zona norte e a zona sul. Em segundo lugar, a busca pelo provimento de água potável foi de fundamental importância para a compreensão da relação da cidade com o maciço e as formas de apropriação do território, que refletem diferentes momentos vividos pela cidade ao longo de 400 anos. É importante ressaltar alguns fatos marcantes na história do Brasil, como a chegada da Família Real, que sem dúvida, influenciou no processo de ocupação e apropriação do território, além do próprio aumento da escassez de água com a chegada da corte portuguesa e de fluxos migratórios devido às atividades econômicas existentes. A dificuldade de abastecimento da cidade fez-se presente durante toda a sua história, estabelecendo uma relação sobre a qual influenciaram ainda mais a situação de escassez de água, como as ocupações residenciais e fabris, assim como o desmatamento para o plantio de café, já no século XVIII, e os processos erosivos e enchentes associadas, conforme aponta Abreu (1992). Já em fins do século XIX e no século XX outros processos que marcam a relação da cidade com o maciço ganham destaque, sobretudo a ocupação residencial tanto na vertente norte (grande Tijuca e grande Méier) como na vertente sul (Botafogo, Humaitá, Jardim Botânico, Gávea e Rocinha) do maciço da Tijuca, aliados a novos significados atribuídos ao lugar, como por exemplo, salubridade e lazer. Contudo, o crescimento da cidade e a necessidade de moradias levaram à ocupação sistemática das bordas do maciço da Tijuca e arredores (Fig. 1) e a intensificação dos processos erosivos, dos escorregamentos e das enchentes.

Sinteticamente, podemos dizer que o maciço da Tijuca (terminologia que engloba a serra da Carioca e serra da Tijuca) sempre exerceu um papel de 

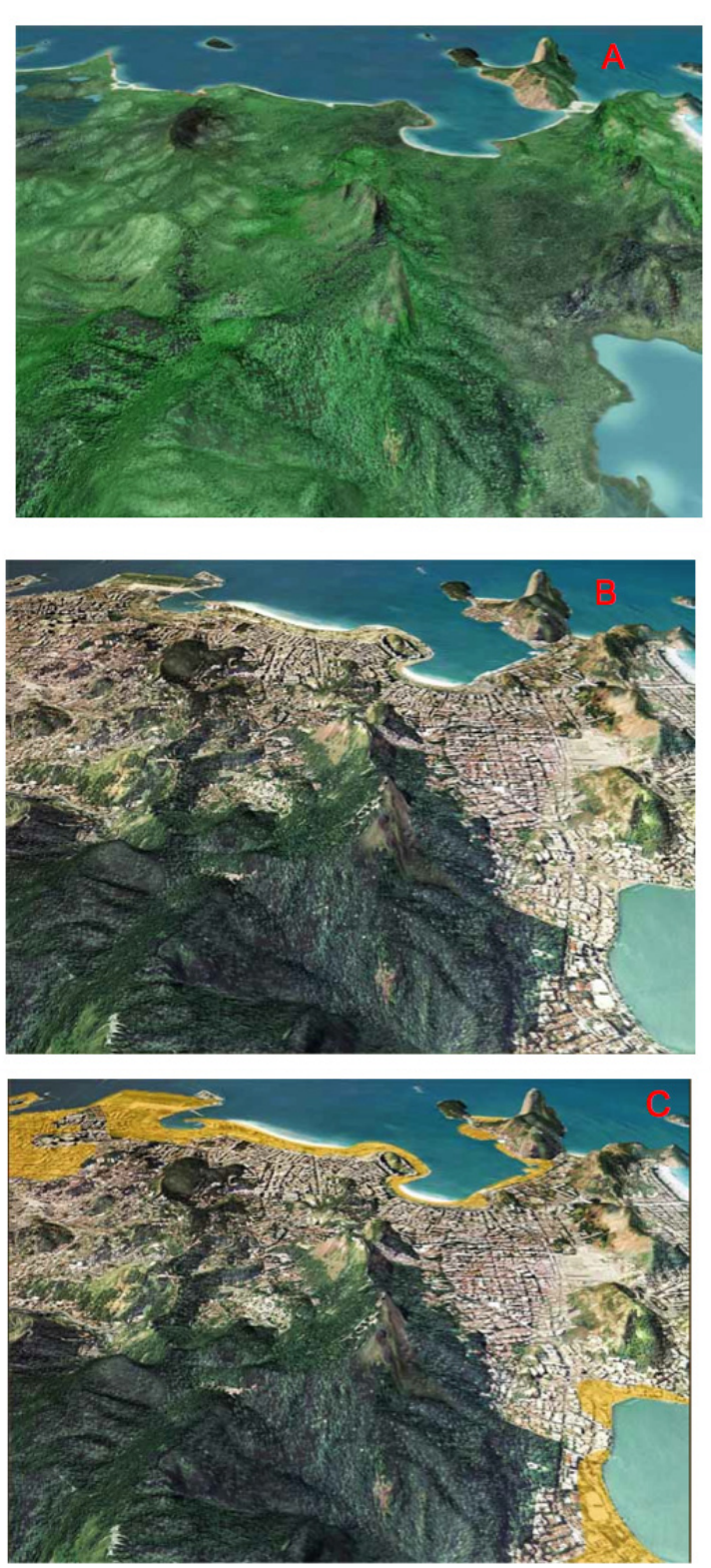

Figura 1. Desenhos esquemáticos realizados pelo Instituto Pereira Passos (IPP) para ilustrar a ocupação de um trecho do Maciço da Tijuca ao longo do tempo: A - a paisagem no ano de 1500 , com presença da Mata Atlântica; B - a paisagem tecnogênica no ano 2000, mostrando o acentuado crescimento ocupacional e, ainda, as áreas representadas pela cor amarela em $\mathrm{C}$ representando os trechos em que ocorreram aterros (Fonte: Artista Gráfico Guta, IPP 2007, URL: http://portalgeo.rio.rj.gov. br/EOUrbana)

destaque para a ocupação e apropriação do território carioca. A cidade, crescendo em volta do maciço e da floresta que fornecia os recursos necessários para seu desenvolvimento socioeconômico, aos poucos, foi transformando a paisagem bucólica do sítio original em materialidades sociais, a partir de diversas intervenções tecnogênicas.

Enquanto a população do Rio de Janeiro teve sua relação com o relevo, mais especificamente, com o maciço da Tijuca embasada na dependência de recursos, sobretudo dependência de água (apesar da diversidade de atividades desenvolvidas ao longo do tempo), em Campos dos Goytacazes e no distrito de Farol de São Tomé (Fig. 2), no norte fluminense, a relação com o sítio (baixada campista) e com a água ocorreram de forma diferenciada.

Ao contrário do processo longo e dificultoso de provimento de água potável para a crescente população da cidade do Rio de Janeiro, o trabalho de Carneiro (2003) evidenciou a ação do Estado, dos produtores rurais, da agroindústria e dos pescadores ao longo da história da baixada campista contra a água. Por longo período, do Brasil colônia até 1970, segundo este autor, a água na região foi considerada um "problema". A questão perpassa por: compreender os aspectos geomorfológicos e geológicos da baixada campista; e compreender a ação do Estado através das obras de drenagem e saneamento e da agroindústria canavieira (grandes usinas a partir e da segunda metade do século XIX).

A constituição da geomorfologia costeira e fluvial local, descrita primeiramente na obra de Lamego (1974), publicada originalmente em 1941, será de fundamental importância para o entendimento da dificuldade de apropriação e uso do território, segundo as "necessidades" impostas pelo capital produtivo. Resumindo, a baixada passou por profundas transformações geológicas no período Quaternário (últimos 2 milhões de anos) a partir da sedimentação do rio Paraíba do Sul e dos eventos de regressão e transgressão marinha (recuo e avanço do mar sobre o continente, respectivamente), originando brejos e lagoas a partir das mudanças sofridas pelo leito do rio Paraíba do Sul. Nos períodos de chuva os rios transbordavam, inundando as planícies adjacentes.

Estes problemas relativos à drenagem das águas e às frequentes enchentes impediam a ocupação sistemática da região para a plantação de cana-de-açúcar. Para a solução do problema, isto é, para a adequação do território às necessidades econômicas dos produtores de cana e dos usineiros foram realizadas várias obras de drenagem, canalização e de aterros. Vigorava a noção de "recuperação de terras", embora estas terras nunca tivessem sido "perdidas". A água era identificada como um entrave ao desenvolvimento econômico (Carneiro 2003). As atividades precisavam de terrenos fir- 


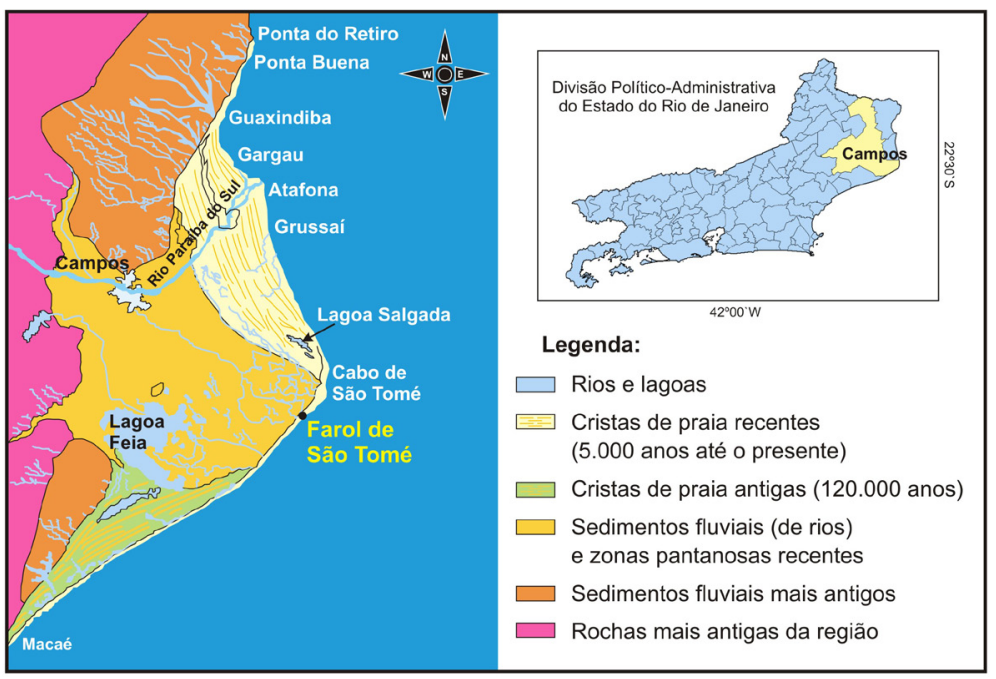

Figura 2. Mapa geológico da região do Delta do rio Paraíba do Sul com destaque para a localização dos municípios de Campos e Farol de São Tomé referidos no corpo do texto; pode-se perceber que a rede de drenagem da região é bem desorganizada e a extensão dos terrenos arenosos de origem fluvial e cristas de praias extremamente porosos (Fonte: http://www.drm.rj.gov. br/admin_fotos/farol_saotome/ mapag.gif)

mes para expansão e parte das áreas embrejadas, das pequenas lagoas e dos reservatórios naturais de água foram drenados e aterrados. A expansão e consolidação da monocultura canavieira só foram possíveis, portanto, a partir da modificação da paisagem, levando a uma intensa reorganização do espaço agrário campista.

Neste caso, a paisagem tecnogênica é a construção material, mediada pela técnica, de condições para uso econômico dos solos da região. Com efeito, esta abordagem pretendeu exemplificar a importância real e simbólica que o relevo assume em diferentes momentos históricos. De área para ocupação residencial, de local para cultivo, até áreas de alto valor geopolítico e estratégico, o relevo tem um relevante papel para a sociedade.

\section{Geomorfologia e Riscos Ambientais}

Os casos destacados anteriormente contribuíram consideravelmente para alterações no ambiente. No caso do maciço da Tijuca, por exemplo, observamos ao longo do tempo a ocorrência de desmatamentos, de queimadas, de erosão e escorregamentos; e na baixada campista, as obras de drenagem alteraram os sistemas fluviais, acelerando processos erosivos fluviais, destruindo ecossistemas e modificando os modos de vida da população local, sobretudo dos pescadores, que se sustentavam com a pesca das áreas drenadas/aterradas. E, assim, outro aspecto que deve ser levado em consideração derivado da apropriação do relevo refere-se aos riscos ambientais. O risco pode ser tomado como uma categoria de análise associada às noções de incerteza, exposição ao perigo, perda e prejuízos materiais, econômicos e de vidas humanas, em função de processos de ordem "natural" (tais como os processos exógenos e endógenos da Terra) e/ou daqueles associados ao trabalho e às relações sociais. Desta forma, o risco refere-se à probabilidade de ocorrência de processos no tempo e no espaço e à maneira como estes processos afetam (direta ou indiretamente) a vida humana (Castro et al. 2005, Castro 2012).

Existem diversas perspectivas de trabalho sobre riscos, sobretudo quando observamos a literatura estrangeira. Podemos encontrar referências a diferentes perigos (hazards) e suas categorias (perigos naturais, tecnológicos e sociais) como elementos para a definição de risco (Hewitt 1997). Alguns autores priorizam o estudo de uma das categorias de perigo supracitadas, ou ainda outras categorias, conforme aponta White et al. (2001), tal qual o perigo biológico, sem fazer menção a outras categorias de perigos. Outros trabalhos, por sua vez, abordam os perigos naturais considerando-os como sinônimos de perigos ambientais, em que o conceito de ambiente encontra-se muito próximo à ideia de natureza.

Aqui, seguimos a proposta de risco ambiental definida por Egler (1996), abrangendo desde a ocorrência de perigos naturais (catástrofes), passando pelos impactos da alocação de fixos econômicos no território, até as condições de vida da sociedade, o que implica avaliações em diferentes escalas e períodos de tempo. Para tanto, o autor utiliza-se das categorias risco natural, risco tecnológico e risco social como componentes do risco ambiental.

Como relacionar então nas aulas de Geografia a Geomorfologia e os riscos ambientais? No item ante- 
rior evidenciamos como o homem se apropria do relevo e dos recursos naturais disponíveis para a satisfação de suas necessidades. Estas necessidades, por sua vez, são satisfeitas pelo trabalho, que para Marx significa: um processo entre o homem e a natureza, um processo pelo qual o homem, através das suas próprias ações, medeia, regula e controla o metabolismo entre ele mesmo e a natureza (Marx 1982). Assim, podemos pensar a relação dialética de transformação homem - natureza através do trabalho.

Sendo assim, podemos nos questionar: o trabalho (em um sentido bem amplo) engendrado pela sociedade moderna tem produzido efetivamente transformações que podem configurar riscos ambientais (sobretudo relacionados ao uso e apropriação do relevo)? Na literatura dos riscos naturais (também conhecidos como "riscos geológicos" ou "riscos geomorfológicos"), observamos que esta categoria está objetivamente relacionada a processos e eventos de origem natural ou induzida por atividades humanas (trabalho). A natureza destes processos é bastante diversa nas escalas temporal e espacial, por isso o risco natural pode apresentar-se com diferentes níveis de perdas, em função da intensidade (magnitude), da abrangência espacial e do tempo de atividade dos processos considerados (Tabela 1). A proposta de abordagem se concretiza a partir da relação dialética entre trabalho (muitas das vezes transcrito por "ação humana"), transformando paisagens, da mesma forma em que o trabalho humano é afetado por diferentes processos da dinâmica superficial ou interna da Terra.

Os riscos naturais, segundo White et al. (2001) estão intrinsecamente ligados ao uso dos recursos naturais e das transformações dos sítios pela sociedade. Para Foucher (1982) os riscos naturais aumentam com o crescimento demográfico e, em uma escala local, aumentam a partir da urbanização dos sítios, frequentemente vulneráveis (planícies aluviais, regiões baixas, sopés de encostas etc).

Nesta matriz simplificada podemos inferir como estes diferentes tipos de risco afetam a vida da sociedade e alteram a paisagem. Os processos que configuram os riscos naturais (erosão, escorregamentos e enchentes) alteram, como já dissemos, o relevo em escala espacial e temporal diferenciadas, em função da magnitude dos processos, do tempo de duração e das características do relevo. Os processos que configuram riscos tecnológicos, por sua vez, podem realizar alterações nas condições ecológicas do solo, do ar e da água de forma gradual, assim como a implementação das indústrias, as aberturas de estradas, os projetos de mineração, entre outros, além da possibilidade de acidentes (explosões, vazamentos de produtos tóxicos, desabamentos, etc.) acarretam mudanças nas formas de relevo em curto prazo de tempo.

As análises de risco ambiental, ou mais especificamente de riscos associados à apropriação do relevo, devem apontar para a tomada de decisão que preserve a sociedade de perigos advindos das implantações de projetos industriais, residenciais e agrários. As análises de risco deveriam ser empreendidas antes da alocação dos investimentos. Desta forma teria a tarefa de desvendar possíveis conflitos ambientais futuros considerando a estrutura da sociedade em classes sociais. Deve-se evitar que as análises de risco sejam meramente protocolos, como etapa cumprida após os investimentos já terem sido alocados, pois acaba por se tornar um instrumento de simples remediação, em vez de um instrumento de planejamento.

\section{Mapas Geomorfológicos: abordagem instrumental}

Dentro deste contexto vale ainda levantar a discussão da abordagem instrumental, que nada mais é do que a Geomorfologia stricto sensu, ou

Tabela 1. Matriz simplificada da relação entre riscos ambientais, processos e relevo.

\begin{tabular}{c|c|c|c}
\hline $\begin{array}{c}\text { Categorias do } \\
\text { Risco Ambiental }\end{array}$ & Processos & Tipos de perdas & $\begin{array}{c}\text { Alterações relevo/ } \\
\text { tempo }\end{array}$ \\
\hline \multirow{2}{*}{ Risco natural } & Erosão, escorregamentos, enchentes & $\begin{array}{c}\text { Perdas materiais e de } \\
\text { vidas humanas }\end{array}$ & $\begin{array}{c}\text { Curto, médio e } \\
\text { longo prazos }\end{array}$ \\
\hline \multirow{2}{*}{ Risco tecnológico } & Poluição ou contaminação solo, águas, & $\begin{array}{c}\text { Prejuízos materiais e à } \\
\text { saúde pública }\end{array}$ & $\begin{array}{c}\text { Curto, médio e } \\
\text { longo prazos }\end{array}$ \\
\cline { 2 - 4 } & $\begin{array}{c}\text { Alterações drásticas da paisagem (estradas, } \\
\text { planta industrial, mineração, acidentes etc.) }\end{array}$ & $\begin{array}{c}\text { Perdas materiais e de } \\
\text { vidas humanas }\end{array}$ & Curto prazo \\
\hline
\end{tabular}


Tabela 2. Exemplos de aplicações dos mapeamentos geomorfológicos (Modif. Cooke e Doornkamp 1991).

\begin{tabular}{|c|c|}
\hline Categoria de Uso & Algumas Aplicações do Mapeamento Geomorfológico \\
\hline Uso da Terra & Planejamento e conservação de áreas culturais e naturais. \\
\hline Regiões agrícolas/florestadas & $\begin{array}{l}\text { Potencial de uso e potencial de perda de solo (erosão); drenagem e } \\
\text { irrigação; recuperação de áreas degradadas. }\end{array}$ \\
\hline Engenharias & $\begin{array}{l}\text { Projetos de instalações industriais; redes de comunicação e transporte; } \\
\text { canalizações, portos, barragens etc. }\end{array}$ \\
\hline Prospecção/exploração mineral & $\begin{array}{c}\text { Áreas de mineração (recuperação, local de depósito de rejeitos, } \\
\text { subsidências e desmoronamentos) }\end{array}$ \\
\hline
\end{tabular}

seja, Geomorfologia como ciência básica. Afinal seria um falacioso engodo discutir a apropriação do relevo, os riscos associados, entre outros aspectos sem ter o adequado conhecimento das formas de relevo e dos processos modeladores. Afinal, como poderíamos ensinar Geomorfologia sem mapear e reconhecer a morfologia? Neste sentido, neste trabalho busca-se o ensino de uma Geomorfologia dita "aplicada", enquanto que a "Geomorfologia ciência básica" seria conteúdo constituinte do ensino superior, sobretudo. Enfim, no ensino escolar deve-se buscar fornecer o suporte para a compreensão do relevo, do uso e da apropriação do território em diferentes contextos históricos.

De acordo com Silva (2002), os mapeamentos geomorfológicos e a sua representação cartográfica adequada são fundamentais para a compreensão da dinâmica de evolução da paisagem ao longo do tempo geológico e fornecem bases para o uso da terra e dos recursos naturais. Como propõem Cooke e Doornkamp (1991) mapas geomorfológicos são documentos úteis para diversos profissionais, sobretudo em relação às questões ambientais (Tabela 2).

Dentro deste contexto, mapas geomorfológicos elaborados em escalas de detalhe e associados a informações de cunho geológico-geomorfológico constituem planos de informação básico ao uso e manejo dos solos. A partir de uma correta interpretação de um documento cartográfico poder-se-ia levantar elementos de susceptibilidade ambiental e de indicação de áreas mais propícias à ocorrência de riscos a eventos de enchentes e/ou de movimentos gravitacionais de massa, por exemplo. É evidente que somente através deste documento não é possível obter informações tão aprofundadas, mas este seria um plano de informação básico e necessário ao reconhecimento de áreas em que seriam necessários estudos mais aprofundados tanto sobre aspectos físico-ambientas, tais como a morfologia, estruturas geológicas, cobertura vegetal, dentre outros, como sobre aspectos de uso e ocupação atual, que iriam buscar subsidiar uma aproximação mais fidedigna da área em estudo.

Vale destacar que para a área coberta pelo mapa, trechos como os maciços costeiros localizados a sul da folha (Pedra Branca e Tijuca) observa-se a localização de relevos escarpados e com presença de falhas e diques reconhecidos, e que certamente correspondem a segmentos mais instáveis ao desencadeamento de fluxos d'água de maior energia e que podem resultar em processos geológico-geomorfológicos de risco, haja vista as áreas ocupadas na base das encostas destes maciços. Assim como, podem corresponder nas áreas de feições planas de planícies que os circundam ao desencadeamento de eventos de enchentes nas épocas de altos índices pluviométricos que assolam a cidade do Rio de Janeiro nos meses de verão.

\section{Considerações Finais}

Os exemplos expostos ao longo do trabalho evidenciam a importância que adquire 'o saber' sobre as características do relevo e seus aspectos evolutivos no auxílio de estudos que balizem a elaboração e implementação de políticas públicas de manejo e utilização dos terrenos de uma área que for analisada. Isso contribui positivamente tanto para o processo de tomada de decisão, como para o entendimento dos mecanismos evolutivos. A partir dessa compreensão podemos contribuir com o debate acerca do ensino de Geomorfologia, apontando para o desenvolvimento de abordagens de trabalho mais lúdicas e próximas da realidade dos discentes, o que tornará a Geomorfologia um assunto cativante e interessante na apreensão do processo de organização espacial de atividades socioeconômicas e de processos físicos. Recomenda-se objetivar e simplificar conteúdos, como 
forma de adequar assuntos geográficos ao ensino.

Sendo assim acreditamos que o desenvolvimento de novas abordagens para o ensino de Geomorfologia no ensino médio e fundamental é de suma relevância. $\mathrm{O}$ trabalho não esgota em si as diversas possibilidades e formas de abordagem desta questão que nos é tão cara. Procuramos ressaltar como o relevo tem sido na história da sociedade, tomado como base para o desenvolvimento das atividades humanas e sua apropriação apresentando um viés real e simbólico. Reiteramos que este trabalho não possui enfoque utilitarista. Não admitimos apenas o relevo como um suporte material fornecedor de recursos e por isso exploramos esta forma de apropriação historicamente marcante na sociedade. Acreditamos que na tentativa de desvendar as formas de apropriação do relevo pelos diferentes grupos sociais podemos fornecer elementos para uma educação que evidencie os riscos e conflitos ambientais (e por extensão, sociais) das diversas formas de uso do solo.

\section{Referências}

Abreu M.A. 1992. A cidade, a montanha e a floresta. In: Abreu, M. A. org. 1992. Natureza e Sociedade no Rio de Janeiro. Rio de Janeiro: Pref. Cid. Rio de Janeiro. p. 54-103. (Col. Bibl. Carioca).

Carneiro P.R.F. 2003. Dos Pântanos à Escassez. Uso da Água e Conflito na Baixada dos Goytacazes. São Paulo: Annablume. Coppe/UFRJ. 138p.

Casseti V. 1999. Contra a Correnteza. Goiânia: Kelps. $139 \mathrm{p}$.

Castro C.M. 2012. Riscos ambientais relacionados à água: por uma gestão territorial da água. Espaço Aberto, 2(1):55-70

Castro C.M., Peixoto M.N.O., Pires do Rio G.A. 2005. Riscos ambientais e geografia: conceituações, abordagens e escalas. Anuário Inst. Geoc. UFRJ, 28(2):11-30.

Cavalcanti L. 2004. Geografia, Escola e Construção de Conhecimentos. 6 ed. Campinas: Papirus. 192p.

Cooke R.U., Doornkamp J.C. 1991. Geomorphology in environmental management: a new introduction. Oxford: Clarendon Press. 410p.

Egler C.A.G. 1996. Risco Ambiental como Critério de Gestão do Território. Território, 1(1):31-41.

Foucher M. 1982. Esquisse d'une Géographie Humaine des Risques Naturels. Hérodote, 24:40-67.

Hewitt K. 1997. Regions of Risk. A Geographical Introduction to Disasters. Essex: Longman. 389p.

Lamego A.R. 1974. O homem e o brejo. Rio de Janeiro: Lidador. 204p.

Marx K. 1982. O capital. Crítica da Economia Política, v.1. São Paulo: Difel. 579p.

Oliva J.T. 1999. Ensino de Geografia: um retardo desnecessário. In: A Geografia na Sala de Aula. São Paulo: Contexto. p. 34-49

Peloggia A.U.G. 1997. A ação do homem enquanto ponto fundamental da Geologia do Tecnógeno: proposição teórica básica e discussão acerca do caso do município de São Paulo. Rev. Bras. Geoc., 27(3):257-268.

Ross J.L.S. 1985. Relevo brasileiro: uma nova proposta de classificação. Rev. Depto. Geografia USP, 4:25-39.

Silva T.M. 2002. A Estruturação Geomorfológica do Planalto Atlantico no Estado do Rio de Janeiro. Rio de Janeiro: Inst. Geoc. PPGG/UFRJ. 265p. (Tese Dout.).

Simielli M.E.R. 1999. Cartografia no Ensino Fundamental e Médio. In: A Geografia na Sala de Aula. São Paulo: Contexto. p.92-108.

Ter-Stepanian G. 1988. Beginning of the Technogene. Paris, Bulletin IAEG, 38:133-142.

Tricart J. 1956. La géomorphologie et la pensée marxiste. La Pensée, 69:55-76.

White G.F., Kates R.K., Burton I. 2001. Knowing Better and Losing even more: the use of knowledge in hazards management. Environm. Hazards, 3:81-92. 